\title{
SHORT-TERM EFFECTS OF TOPICAL LEVOBUNOLOL ON THE HUMAN RETINAL CIRCULATION
}

\author{
MELISSA LEUNG and JUAN E. GRUNWALD \\ Philadelphia, Pennsylvania
}

\begin{abstract}
SUMMARY
Purpose: The effect of topical levobunolol $\mathrm{HCl} 0.5 \%$ on the retinal circulation was studied on 15 normal volunteers aged 21-54 years (32 \pm 10 years).

Methods: In a double-masked, randomised design, one eye of each subject received a drop of levobunolol HCl $0.5 \%$ (LEV) and the fellow eye received a drop of artificial tears (TEAR). Leucocyte velocity $\left(V_{\mathrm{BFS}}\right)$ and density in the retinal macular microcirculation were measured by the blue-field simulation technique. Venous diameter $(D)$, maximum erythrocyte velocity $\left(V_{\max }\right)$ and volumetric blood flow rate $(Q)$ were measured in a major temporal vein by laser Doppler velocimetry and monochromatic fundus photography. Results: The following average changes from baseline were observed 2 hours after treatment: heart rate, $-4.6 \pm 8.3 \% \quad(p=0.04) ; \quad$ intraocular pressure, $-31.7 \pm 10.6 \%(p=0.0001)$; and perfusion pressure, $15.4 \pm 14.4 \%(p=0.02)$ in LEV eyes; no statistically significant changes in IOP and perfusion pressure were seen in TEAR eyes. When each eye was compared with its own baseline, there were no significant changes in $V_{\mathrm{BFS}}$, density, $D, V_{\max }$ and $Q$ in LEV eyes. In TEAR eyes, there were no significant changes in $V_{\mathrm{BFS}}$, density, $V_{\max }$ and $Q$, but a significant change in $D$ $(-1.8 \pm 2.6 \% ; p=0.02)$ was observed. A significant average percentage increase in $Q$ of $10.9 \pm 19.2 \%$ (paired $t$-test between the change after LEV and the change after TEAR, $p=0.044$ ) was seen in LEV eyes when compared with TEAR eyes. Twelve of the 15 subjects demonstrated a relative increase in $Q$ in the LEV eyes in comparison with the TEAR eyes, while 3 subjects showed the opposite.

Conclusion: A significant difference in the effect of levobunolol between the two eyes was detected, even though there was no statistically significant effect when each eye was compared with its baseline.
\end{abstract}

From: Department of Ophthalmology, Scheie Eye Institute, School of Medicine, University of Pennsylvania, Philadelphia, USA.

Correspondence to: Dr Juan E. Grunwald, Scheie Eye Institute, 51 North 39th Street, Philadelphia, PA 19104, USA.
Levobunolol is a non-selective beta-adrenergic antagonist with no intrinsic sympathomimetic activity which is widely used in the treatment of ocular hypertension and glaucoma. By binding to receptor sites on the ciliary epithelium, beta-blockers cause a decrease in aqueous humour production and a consequent lowering of intraocular pressure (IOP). ${ }^{1}$

Beta-blockers have been shown to have an effect on the retinal circulation. ${ }^{2-7}$ If, as recent studies have suggested, retinal blood flow is decreased in openangle glaucoma, ${ }^{8}$ any interference with the rate of flow could be important. For this reason, a careful assessment of the retinal vascular effects of commonly used anti-glaucomatous compounds is warranted. This point is of particular importance in glaucoma patients who are also affected by retinovascular diseases. ${ }^{9}$

This report summarises a study of the effect of a single dose of levobunolol $0.5 \%$ on retinal circulation utilising two different methods: (1) the blue-field simulation technique, which assesses the retinal macular microcirculation; and (2) a combination of bidirectional laser Doppler velocimetry and monochromatic fundus photography, which measures the circulation of the main retinal vessels. To our knowledge, this is the first study to use these two techniques to simultaneously assess the effect of a pharmacological compound on these two aspects of the retinal circulation.

\section{MATERIALS AND METHODS}

Fifteen volunteers aged $21-54$ years (mean \pm 1 SD, $32 \pm 10$ years), with no history of systemic or ocular diseases, were included in this study. All had a bestcorrected visual acuity of 20/20, an IOP of $18 \mathrm{mmHg}$ or less, and normal anterior segment and fundus. None of the subjects had taken any systemic or topical medications within the 2 weeks prior to the study, and caffeine had not been ingested within 24 hours before the study. Informed consent was 
obtained from each volunteer. The research followed the tenets of the Declaration of Helsinki and was approved by the institutional Human Experimentation Committee.

\section{Blue Field Simulation Method (BFS)}

The retinal macular microcirculation was assessed using the blue-field simulation technique (BFS) (Oculix BFS-2000, Berwyn, PA), following pupillary dilatation with tropicamide $1 \%$ (Alcon, Humacao, Puerto Rico). The BFS technique is based on the blue-field entoptic phenomenon, which consists of the perception of leucocytes flowing through the subject's own retinal macular vasculature.

Quantification of the mean velocity $\left(V_{\mathrm{BFS}}\right)$ and density (number per field of observation) of these leucocytes was performed using BFS in which the subjects adjusted the number and velocity of computer-simulated leucocytes moving on a video screen to match those of their own entopically perceived leucocytes. During each trial, the velocity was scrambled by the computer but the density remained unchanged in order to simplify and shorten each trial. However, the subjects were asked to make the corresponding adjustments if their perceived density had changed during the experiment.

In order to assess the subject's accuracy in matching their own perceived leucocytes to those of computer-simulated ones, five trials were first performed (using the right eye) where each subject adjusted a computer-simulated set of leucocytes to match those of a standard simulation..$^{10}$ All subjects in this study adjusted $V_{\mathrm{BFS}}$ of the simulated blue field to within less than $20 \%$ of the standard $(6 \pm 8 \%)$. Subjects then performed ten BFS trials in each eye to obtain a baseline average $V_{\mathrm{BFs}}$ and density.

\section{Bidirectional Laser Doppler Velocimetry and Monochromatic Fundus Photography}

A Polaroid colour fundus photograph of the disc was then taken. Bidirectional laser Doppler velocimetry (BLDV) measurements of red blood cell (RBC) velocity in a main superior or inferior temporal vein were obtained in both eyes. To simplify the determination of the average velocity, BLDV measurements were performed in the veins where there is minimal flow pulsatility. The velocity was measured on straight portions of the vessels, at a distance less than two disc diameters from the optic nerve head centre. Venous junctions, arteriovenous crossing, or sites where two vessels were in close proximity, were avoided. The location of the measurement site was marked on the Polaroid photograph. Detailed descriptions of the BLDV technique have been published previously, ${ }^{11,12}$ so only a brief summary will be provided here.
The maximum or centreline velocity of the RBCs $\left(V_{\max }\right)$ was determined according to the relation: $V_{\max }=k \Delta f_{\mathrm{avg}}$, where $k$ is a constant related to the scattering geometry and the wavelength of the laser light. $\Delta f=f_{1 \max }-f_{2 \max }$ where $f_{1 \max }$ and $f_{2 \max }$ are the cut-off frequencies of the Doppler shift power spectra recorded simultaneously in two different directions of the scattered light. Approximately 20 pairs of power spectra were used to calculate an average $\Delta f\left(\Delta f_{\text {avg }}\right)$ from which $V_{\max }$ was then obtained.

Immediately following the BLDV recordings, fundus photographs were taken in monochromatic light at $570 \mathrm{~nm}$ using a Zeiss (Carl Zeiss, Oberkochen, Germany) fundus camera and Kodak (Eastman Kodak, Rochester, NY) Plus-X pan film. The diameter of the veins $(D)$ at the site of the BLDV recordings, averaged from six photographs, was measured from projected photographic negatives. Both fundus photographs and the BLDV data were obtained with the subject sitting in a darkened room.

The retinal volumetric blood flow rate was calculated as $Q=V_{\text {mean }} \times \pi D^{2} / 4$, where $V_{\text {mean }}$ represents the mean velocity of whole blood. $V_{\text {mean }}$ was calculated assuming $V_{\text {mean }}=C \times V_{\text {mean }}$, where $C$ is the same constant for all vessels measured. A value of $C=1 / 1.6$ was taken from the previous work of Damon and Duling, ${ }^{13}$ who studied the relationship between $V_{\max }$ and $V_{\text {mean }}$ using glass tubes.

While the subject remained in the sitting position and immediately after BLDV measurements and monochromatic fundus photography (MFP) were done, the subject's brachial artery systolic and diastolic blood pressure and heart rate (HR) were measured using an automated sphygmomanometer (Datascope Accutorr, Paramus, NJ). Two drops of topical proparacaine $\mathrm{HCl} 0.5 \%$ (Allergan Pharmaceuticals, Hormigueros, Puerto Rico) were instilled in each eye, and the IOP was measured by Goldmann applanation tonometry.

One drop of levobunolol $\mathrm{HCl}$ 0.5\% (Betagan Liquifilm, Allergan, Irvine, CA) was then instilled in one eye of each subject in a double-masked, randomised fashion, while the other eye received one drop of Liquifilm Tears (Allergan). Each subject applied finger pressure to occlude the nasolacrimal ducts of both eyes for 2 minutes, in order to minimise systemic distribution of the drug while maximising its intraocular penetration. ${ }^{14}$ Two hours later, the above-mentioned experimental procedure was repeated in the same sequence. The subjects were asked to not eat or drink during this 2 hour period. An additional drop of tropicamide $1 \%$ was instilled in the middle of this 2 hour period to ensure good pupillary dilatation throughout the measurements. (Tropicamide has failed to show any significant effect 
on macular leucocyte velocity and presumably blood flow. ${ }^{15}$ )

Mean brachial artery blood pressure, $\mathrm{BP}_{\mathrm{m}}$, was calculated using the relation: $\mathrm{BP}_{\mathrm{m}}=\mathrm{BP}_{\mathrm{d}}+1 / 3$ $\left(\mathrm{BP}_{\mathrm{s}}-\mathrm{BP}_{\mathrm{d}}\right)$, where $\mathrm{BP}_{\mathrm{s}}$ and $\mathrm{BP}_{\mathrm{d}}$ are the brachial artery systolic and diastolic pressure, respectively. Perfusion pressure, $\mathrm{PP}$, was calculated as $\mathrm{PP}=2 / 3$ $\mathrm{BP}_{\mathrm{m}}-\mathrm{IOP}$.

All vessel diameters were measured by one trained examiner and all $V_{\max }$ determinations by another. Each examiner was masked with regard to the following: (1) the results of the other; (2) whether measurements were obtained at baseline or after treatment; (3) the eye that received levobunolol.

The data were analysed statistically using the twotailed paired and non-paired Student's $t$-test, linear regression and correlation analysis. Findings with an error probability value smaller than 0.05 were considered to be statistically significant.

\section{RESULTS}

Table I shows the average measurements of IOP and PP before and after the application of Liquifilm Tears or levobunolol. Two hours after the instillation there was no significant change in the average blood pressure (mean $\pm 1 \mathrm{SD}, 2.0 \% \pm 8.6 \%$; paired Student's $t$-test, $p=0.431$ ), but there was a significant decrease in the heart rate of $4.6 \% \pm 8.3 \%$ $(p=0.039)$. IOP significantly decreased by an average of $31.7 \% \pm 10.6 \%$ in the levobunolol-treated (LEV) eyes (paired $t$-test between baseline and after treatment in LEV eyes, $p<0.0001$ ) and non-significantly decreased by $1.3 \% \pm 13.9 \%$ in the Liquifilm Tears (TEAR) eyes (paired $t$-test between baseline and after treatment in TEAR eyes, $p=0.495)$. PP increased significantly in the LEV eyes by $15.4 \% \pm 14.4 \% \quad(p=0.013)$ and increased non-significantly by $3.9 \% \pm 13.8 \%$ in the TEAR eyes

Table I. Following treatment, the average percentage change from baseline in intraocular pressure (IOP), perfusion pressure (PP), mean leucocyte velocity (VBFS), leucocyte density (Density), venous diameter $(D)$, maximum velocity of red blood cells $\left(V_{\max }\right)$ and volumetric blood flow rate $(Q)$ in the Liquifilm treated eyes (TEAR) and the levobunolol-treated eyes (LEV)

\begin{tabular}{lrc}
\hline & TEAR & LEV \\
\hline IOP & $-1.3 \pm 13.9$ & $-31.7 \pm 10.6^{* *}$ \\
PP & $3.9 \pm 13.8$ & $15.4 \pm 14.4^{*}$ \\
BFS method & & \\
VBFS & $-2.1 \pm 21.5$ & $0.4 \pm 10.7$ \\
Density & $-4.4 \pm 25.1$ & $3.8 \pm 31.9$ \\
MFP and BLDV method & & \\
$D$ & $-1.8 \pm 2.6^{*}$ & $0.6 \pm 2.9$ \\
$V_{\max }$ & $-1.7 \pm 11.0$ & $4.9 \pm 14.3$ \\
$Q$ & $-5.1 \pm 11.8$ & $5.9 \pm 13.2$ \\
\hline
\end{tabular}

Values are the mean $\pm \mathrm{SD}$.

BFS, blue-field simulation; MFP, monochromatic fundus photography; BLDV, bidirectional laser doppler velocimetry.

${ }^{*} p<0.05$.

**Significantly different from baseline by two-tailed paired Student's $t$-test, $p<0.001$. $(p=0.389)$. Both the average percentage decrease in IOP of $-30.4 \% \pm 13.8 \%$ and the increase in PP of $11.5 \% \pm 5.8 \%$ were significantly greater in the LEV eyes than in the TEAR eyes (paired $t$-test between the change after LEV and the change after TEAR, $p<0.0001)$.

\section{BFS Results}

Table I presents the average measurements of $V_{\mathrm{BFS}}$ and density before and after the application of Liquifilm Tears or levobunolol. Following treatment, there were no significant changes from baseline in average $V_{\mathrm{BFS}}(0.4 \% \pm 10.7 \%$, Table I) or density $(3.8 \% \pm 31.9 \%)$ in the LEV eyes. In the TEAR eyes, there were also no significant changes from baseline values in average $V_{\mathrm{BFS}}(-2.1 \% \pm 21.5 \%)$ or density $(-4.4 \% \pm 25.1 \%)$. When compared with the changes observed in the TEAR eyes, the LEV eyes showed non-significant average changes in $V_{\mathrm{BFS}}$ of $2.5 \% \pm$ $16.5 \%$ (paired $t$-test between the change after LEV and the change after TEAR, $p=0.571)$ and in density of $8.3 \% \pm 32.2 \%(p=0.334)$.

\section{$B L D V$ and MFP Results}

Table I gives the average measurements of diameter, $V_{\text {max }}$ and volumetric blood flow rate in each eye before and after the application of Liquifilm Tears or levobunolol.

Following treatment, there were no significant changes from baseline in average diameter $\left(0.6 \% \pm 2.9 \%\right.$, Table I), $V_{\max }(4.9 \% \pm 14.3 \%)$ or volumetric blood flow rate $(5.9 \% \pm 13.2 \%)$ in the LEV eyes. In the TEAR eyes, there were also no significant changes from baseline in average $V_{\max }$ $(-1.7 \% \pm 11.0 \%)$ or volumetric blood flow rate $(-5.1 \% \pm 11.8 \%)$, but a significant decrease in diameter $(-1.8 \% \pm 2.6 \%$; paired $t$-test between baseline and after treatment in TEAR eyes, $p=0.018)$. When compared with the changes observed in the TEAR eyes, the LEV eyes showed non-significant changes in $V_{\max }$ of $6.6 \% \pm 19.0 \%$ (paired $t$-test between the change after LEV and the change after TEAR, $p=0.717)$. However, the average percentage change in volumetric blood flow rate of $10.9 \% \pm 19.2 \%$ and of $2.4 \% \pm 3.2 \%$ in diameter were statistically significant in the LEV eyes when compared with TEAR eyes ( $p=0.044$ and $p=0.011$, respectively). Fig. 1 shows a comparison of the percentage change in volumetric blood flow rate from baseline in TEAR eyes and in LEV eyes for each subject.

There were no statistically significant correlations between percentage changes in $\mathrm{BP}_{\mathrm{m}}$, IOP or $\mathrm{PP}$ and the percentage changes in $V_{\mathrm{BFS}}$, density, diameter, $V_{\text {max }}$ or volumetric blood flow rate. Furthermore, there were no statistically significant correlations between BFS measurements of macular microcircu- 


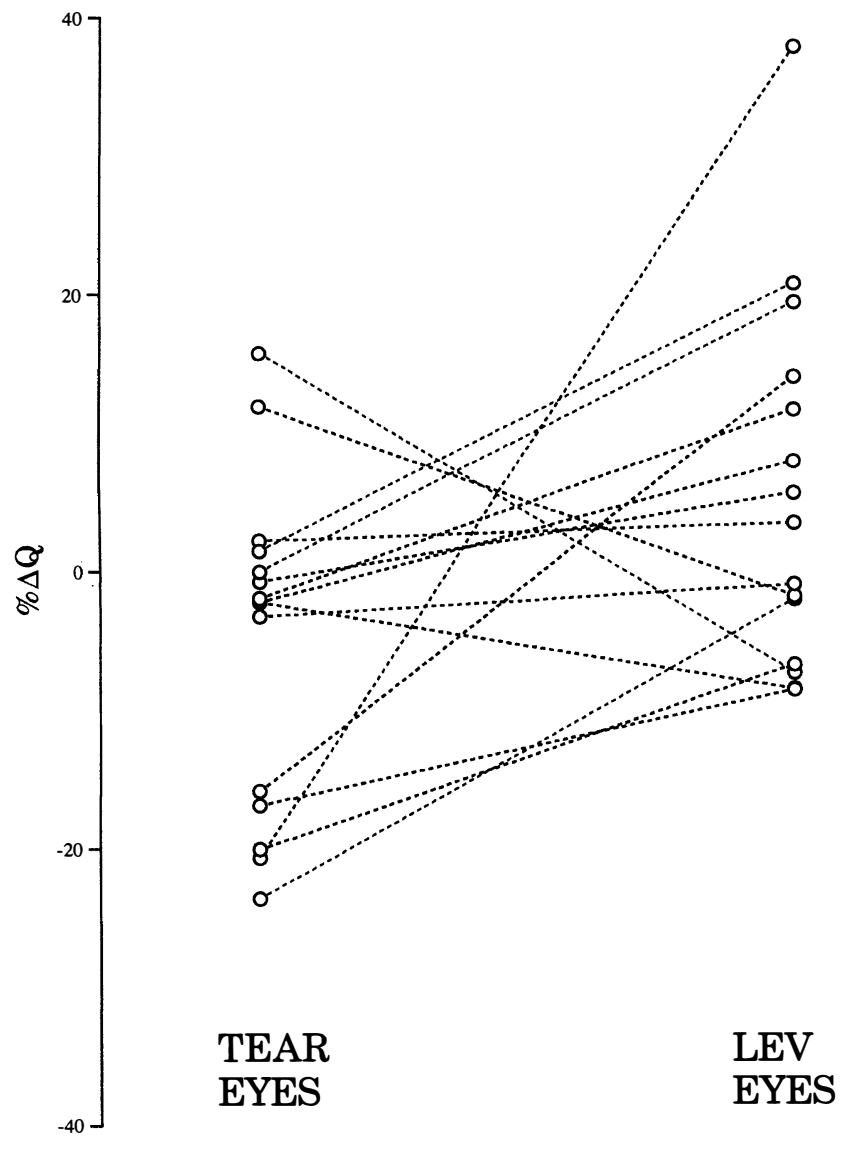

Fig. 1. Percentage change from baseline in volumetric blood flow rate $(\% \Delta \mathrm{Q})$ in Liquifilm-treated eyes (TEAR eyes) and in levobunolol-treated eyes (LEV eyes) for each subject.

latory parameters and BLDV and MFP determinations of blood flow in the major retinal veins.

Subjects were divided into two groups according to iris colour. Eight subjects had brown irises and seven had blue/green irises. In LEV eyes, volumetric blood flow rate increased from baseline by an average of $0.1 \% \pm 8.3 \%(p=0.937)$ in the group with brown irises while in the group with blue/green irises it increased by an average of $10.9 \% \pm 15.2 \%$ $(p=0.093)$. The difference in average percentage increase in volumetric blood flow rate between the two groups, however, was of borderline significance (paired $t$-test between the change in $Q$ in blue/green irises and the change in brown irises after LEV treatment, $p=0.057)$. In the TEAR eyes, the browncoloured iris group showed an average decrease in volumetric blood flow rate from baseline of $5.5 \% \pm 12.8 \% \quad(p=0.459)$ while the blue/greencoloured iris group had a decrease of $4.7 \% \pm 11.8 \% \quad(p=0.331)$; the average percentage difference between these two groups was not statistically significant (paired $t$-test between the change in $Q$ in blue/green irises and the change in brown irises after TEAR treatment, $p=0.886$ ).

\section{DISCUSSION}

This is the first study in which two methods have been used to investigate the effects of levobunolol on two different aspects of the retinal circulation, i.e. the large retinal veins and the macular microcirculation.

The results of our study show that topical levobunolol significantly reduced IOP and, therefore, increased PP. In the LEV eyes, volumetric blood flow rate increased from baseline by $5.9 \%$ and this change was not statistically significant. When the percentage changes in the LEV eyes were compared with the percentage changes in TEAR eyes, however, a statistically significant difference of $11 \%$ was observed (paired $t$-test, $p=0.044$; Fig. 1). Furthermore, as seen in Fig. 1,12 of the 15 subjects demonstrated a relative increase in volumetric blood flow rate in the LEV eyes in comparison with the TEAR eyes, while 3 subjects showed the opposite.

Although the average increase from baseline of $5.9 \%$ in LEV eyes was not significant, this trend was in the same direction as that reported by us following topical instillation of timolol maleate. ${ }^{2-4}$ However, using the same technique, Yoshida et al. ${ }^{5}$ did not detect any changes in retinal blood flow following timolol instillation. Their very small sample size of only 5 subjects strongly suggests that their statistical power to detect a difference may have been very weak. We have also reported that carteolol ${ }^{16}$ failed to show any statistically significant effect on the retinal circulation. Using fluorescein angiography, Schulte et al. ${ }^{6}$ showed that metipranolol significantly increases retinal arterial mean dye velocity by $12 \%$. Using a somewhat similar methodology, Weber ${ }^{7}$ reported increases in retinal circulation times following treatment with timolol and pindolol, but the lack of appropriate control experiments does not allow any strong conclusions to be made from these results.

Our BFS results, unlike those of retinal blood flow in the major retinal veins, did not show any significant effects of levobunolol on the macular microcirculation. This is similar to previous studies of various beta-blockers (betaxolol, ${ }^{17-19}$ timolol, $^{18-20}$ carteolol $^{19}$ and levobunolol ${ }^{19}$ ) which failed to detect any effect on leucocyte velocity and density in the macular microcirculation.

Since in our study we did not find any significant percentage changes in $V_{\mathrm{BFS}}$ and density after the instillation of the drops, we calculated the sensitivity of the measurements to determine the minimum changes that the technique used could have detected. Sensitivity of $V_{\mathrm{BFS}}$ was calculated to be $9.8 \%$ using the following equation derived from the formula used to calculate $t$ for paired observations: ${ }^{21}$

$$
\frac{\Delta V_{\mathrm{BFS}}}{V_{\mathrm{BFS}}}(\%)=\frac{\mathrm{SD} \times T}{15 \times V_{\mathrm{BFS}}} \times 100
$$


where $V_{\mathrm{BFS}}$ is the average of the absolute changes in leucocyte velocity, SD is the standard deviation of $V_{\mathrm{BFS}}, T$ is the $t$ value for 14 degrees of freedom at a significance level of $p<0.05$ (two-tailed) and 15 is the number of subjects. Similarly, the sensitivity for density was $17.6 \%$; any average percentage change smaller than these values could not be detected using our techniques.

Our results show a significant vasoconstriction in the TEAR eyes, which is somewhat surprising and points to a possible systemic effect of the levobunolol instilled in the fellow eye. This is supported by the fact that levobunolol also produced a systemic decrease in heart rate of $4.6 \%$. We also cannot exclude the possibility that the artificial tear preparation may have some vasoconstrictive properties.

Even though the retinal circulation is thought to have no direct autonomic innervation and is largely auto-regulated ${ }^{22-26}$ studies have shown the presence of adrenergic receptors in the retinal vessels. ${ }^{27-30} \mathrm{We}$ therefore cannot exclude the possibility that levobunolol could reach through the systemic circulation to adrenergic receptors present in the vasculature of the contralateral eye and produce an effect on them.

We do not have a good explanation for the lack of significant effect on vessel diameter in the LEV eyes. It is possible that differences in the drug concentrations reached in each eye could elicit different responses or that a local effect of the drug could mask a systemic effect of the drug.

No correlations were detected between haemodynamic parameters measured by BFS in the macular microcirculation and those measured by BLDV and MFP in the major temporal veins. Although the two techniques measure very different parameters, this lack of significant correlation suggests that the drug may affect these two aspects of the retinal circulation differently. The macula is a very specialised area of the retina and it is possible that it may have different metabolic requirements and vascular responses compared with the more peripheral retina.

The pharmacokinetics of levobunolol may be affected by the amount of pigmentation in the subject's eyes. Because there is greater melanin concentration in the ciliary body and retinal pigment epithelium in eyes with brown irises than in eyes with blue/green irises, ${ }^{31}$ drugs that bind to melanin exhibit a greater decrease in availability in brown eyes compared with blue eyes. Beta-adrenergic blockers have an aromatic and amino moiety that binds to melanin. ${ }^{32}$ Consequently, initial levels of unbound beta-blockers may be lower in eyes with browncoloured irises than in those with blue- or greencoloured irises. Release of the drug from its attachment to melanin may cause an increase in the duration of action in heavily pigmented eyes. ${ }^{32}$ In fact, timolol has been shown to cause less of a decrease in IOP in eyes with brown irises than in eyes with blue irises. ${ }^{33}$

In our study, LEV eyes showed a trend toward larger increases in $Q$ in blue/green eyes when compared with brown eyes $(p=0.057)$. Reduced availability of levobunolol could cause this trend towards a smaller effect of the drug in more pigmented eyes. Variations in iris colour between studies could thus explain some of the differences in the results of different studies.

In summary, our results suggest that although there was no statistically significant effect when each eye was compared with its baseline, a significant difference in the effect between the two eyes was detected. This difference between the two eyes could be in part due to a systemic effect of levobunolol producing a tendency towards a decrease in volumetric blood flow rate in the TEAR eyes. Further studies are needed to elucidate the mechanisms producing these effects.

This work was supported by a grant from Allergan Pharmaceuticals and the Vivian Lasko Research Fund.

Key words: Retinal blood flow, Levobunolol, Human retina, Laser Doppler velocimetry, Blue field simulation.

\section{REFERENCES}

1. Brooks AM, Gillies WE. Ocular beta-blockers in glaucoma management: clinical pharmacological aspects. Drugs Aging 1992;2:208-21.

2. Grunwald JE. Effect of timolol on human retinal circulation. Invest Ophthalmol Vis Sci 1986;27:1713-9.

3. Grunwald JE. Effect of two weeks of timolol maleate treatment on the normal retinal circulation. Invest Ophthalmol Vis Sci 1991;32:39-45.

4. Grunwald JE. Effect of timolol maleate on the retinal circulation of human eyes with ocular hypertension. Invest Ophthalmol Vis Sci 1990;31:521-6.

5. Yoshida A, Feke GT, Ogasawara H, Goger DG, Murray DL, McMeel W. Effect of timolol on human retinal, choroidal and optic nerve head circulation. Ophthalmic Res 1991;23:162-70.

6. Schulte K, Wolf S, Werner E, Remky A, Arend O, Reim M. Effect of metipranolol on the retinal circulation in humans. Invest Ophthalmol Vis Sci 1992;33(Suppl):1078.

7. Weber GRJ. Der Eisfluss der Betablocker timolol und pindolol auf die retinale Hemodynamik:eine videoangiographische Studie. Klin Monatsbl Augenheilkd 1987;190:34-9.

8. Wolf S, Arend O, Sponsel WE, Schulte K, Cantor LB, Reim M. Retinal hemodynamics using scanning laser ophthalmoscopy and hemorrheology in chronic openangle glaucoma. Ophthalmology 1993;100:1561-6.

9. Kolker AE, Hetherington J. In: Becker-Schaffer's diagnosis and therapy of the glaucomas. St Louis: CV Mosby, 1983:245.

10. Grunwald JE, Zinn H. The acute effect of oral acetazolamide on macular blood flow. Invest Ophthalmol Vis Sci·1992;33:504-7.

11. Riva CE, Grunwald JE, Sinclair SH, Petrig BL. Blood velocity and volumetric flow rate in human retinal vessels. Invest Ophthalmol Vis Sci 1985;26:1124-32. 
12. Riva CE, Feke CT. Laser Doppler velocimetry in the measurement of retinal blood flow. In: Goldman L, editor. The biomedical laser: technology and clinical applications. New York: Springer, 1981:135-61.

13. Damon DN, Duling BR. A comparison between mean blood velocities and center-line red cell velocities as measured with a mechanical image streaking velocimeter. Microvasc Res 1979;17:330-2.

14. Salminen L. Review: Systemic absorption of topically applied ocular drugs in humans. J Ocul Pharmacol 1990;6:243-9.

15. Robinson F, Petrig BL, Sinclair SH, Riva CE, Grunwald JE. Does topical phenylephrine, tropicamide, or proparacaine affect macular blood flow? Ophthalmology 1985;92:1130-2.

16. Grunwald JE, Delehante J. Effect of topical carteolol on the normal human retinal circulation. Invest Ophthalmol Vis Sci 1992;33:1853-6.

17. Friedlander S, DeMaio R, Sinclair S, Werner E. The acute effects of betaxolol on human macular hemodynamics in normals. Invest Ophthalmol Vis Sci 1992; 33(Suppl):810.

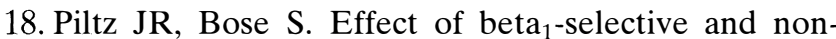
selective beta blockers on macular blood flow and contrast sensitivity. Invest Ophthalmol Vis Sci 1994; 35(Suppl):1659.

19. Burgoyne JE, Harris A, Shoemaker JA, Weinland M, Phillips C, Cantor LB, et al. Perimacular hemodynamic effects of betaxolol, carteolol and levobunolol. Invest Ophthalmol Vis Sci 1994;35(Suppl):1388.

20. Chen S, Robinson F, Petrig BL, Grunwald JE, Riva CE. The acute effect of topical timolol on human macular capillary blood flow. Invest Ophthalmol Vis Sci 1993;34(Suppl):1394.

21. Colton T. In: Statistics in medicine. Boston: Little, Brown, 1974:134.

22. Sears ML. Autonomic nervous system: adrenergic agonists. In: Sears ML, editor. Pharmacology of the eye. Berlin: Springer, 1984:206.
23. Alm A, Bill A. The oxygen supply to the retina. II. Effects of high intraocular pressure and of increased arterial carbon dioxide tension on uveal and retinal blood flow in rats. A study with radioactively labelled microspheres including flow determinations in brain and some other tissues. Acta Physiol Scand 1972; 84:306-19.

24. Geijer C, Bill A. Effects of raised intraocular pressure on retinal, prelaminar, laminar, and retrolaminar optic nerve flow in monkeys. Invest Ophthalmol Vis Sci 1979;18:1030-42.

25. Riva CE, Sinclair SH, Grunwald JE. Autoregulation of retinal circulation in response to decrease of perfusion pressure. Invest Ophthalmol Vis Sci 1981;21:34-8.

26. Grunwald JE, Sinclair SH, Riva CE. Autoregulation of the retinal circulation in response to decrease of intraocular pressure below normal. Invest Ophthalmol Vis Sci 1982;23:124-7.

27. Forster BA, Ferrari-Dileo G, Anderson D. Adrenergic alpha $_{1}$ and alpha 2 binding sites are present in bovine retinal blood vessels. Invest Ophthalmol Vis Sci 1987;28:1741-6.

28. Ferrari-Dileo G. Beta ${ }_{1}$ and beta 2 adrenergic binding sites in bovine retina and retinal blood vessels. Invest Ophthalmol Vis Sci 1988;29:695-9.

29. Hoste AM, Boels PJ, Brutsaert DL, deLaey JJ. Effect of alpha ${ }_{1}$ and beta agonists on contraction of bovine retinal resistance arteries in vitro. Invest Ophthalmol Vis Sci 1989;30:44-50.

30. Busch MJ, Stjernschantz J, Hoyng PF. Increase in ocular blood flow induced by isobutylmethylxanthine and epinephrine. Exp Eye Res 1991;52:199-204.

31. Menom IA, Wakeham DC, Persad GD, Avaria M, Trope GE, Baeu PK. Quantitative determination of the melanin contents in ocular tissues from human blue and brown eyes. J Ocul Pharmacol 1992;6:35-42.

32. Nagata A, Mishima HK, Kiuchi Y, Hirota A, Kurokawa T, Ishibashi S. Binding of antiglaucomatous drugs to synthetic melanin and their hypotensive effects on pigmented and non-pigmented rabbit eyes. Jpn J Ophthalmol 1993;37:32-8.

33. Salminen L, Imre G, Huupponen R. The effect of ocular pigmentation on intraocular pressure response to timolol. Acta Ophthalmol Suppl (Copenh) 1985; 173:15-8. 